\section{Adolescent e-cigarette use: A public health crisis}

The use of electronic cigarettes (e-cigarettes) in teenagers has been increasing rapidly in the United States, leading Surgeon General Jerome Adams, MD, $\mathrm{MPH}$, to label it a public health concern. ${ }^{1}$ Easy accessibility and extensive marketing for e-cigarettes counteract public education campaigns and policies aimed at decreasing e-cigarette use in teenagers.

E-cigarettes are marketed to teenagers as small, easy-to-use pens or USB flash drive-like devices that can be hidden easily. Some devices can be used to smoke nicotine, delta-9-tetrahydrocannabinol (THC), cannabidiol, and butane hash oil. Some are sold with different nicotine flavors to increase their appeal. E-cigarette ads appear in retail stores, movies, magazines, newspapers, and on the internet.

According to the CDC, the number of middle and high school students using e-cigarettes increased from 3.6 million in 2018 to 5.4 million in 2019 . $^{2}$ Nicotine dependence from e-cigarette use can increase the risk of starting to smoke cigarettes. A 2015-2016 National Institute on Drug Abuse survey found a higher prevalence of e-cigarette use among 9th-, 10th-, and 12th-grade students compared with cigarette smoking $(9.5 \%, 14 \%, 16.2 \%$ vs $3.6 \%, 6.2 \%$,

\section{Keep in touch!}

\section{Ietters@currentpsychiatry.com}

OR

Comments \& Controversies

CuRrent Psychiatry

7 Century Drive, Suite 302

Parsippany, NJ 07054

All letters are subject to editing.
$11.4 \%$, respectively). ${ }^{3}$ Due to the growing popularity of vaping among adolescents in the United States, Congress recently raised the legal age to purchase tobacco and vaping products to 21 years.

Evidence of adverse health effects associated with e-cigarette use continues to grow. In 2020, the Department of Health and Services in Wisconsin and the Department of Public Health in Illinois looked at e-cigarette use and pulmonary disease. ${ }^{4}$ Of 98 participants who reported e-cigarette use, $97 \%$ presented with respiratory symptoms, $77 \%$ had gastrointestinal symptoms, and $100 \%$ had constitutional symptoms. Chest imaging showed bilateral infiltrates in all patients. In addition, 95\% were hospitalized, $26 \%$ underwent intubation and mechanical ventilation, and 1 patient died. Most participants (89\%) reported using THC in their e-cigarette devices. ${ }^{4}$ Blount et $\mathrm{al}^{5}$ recently found a link between e-cigarette- or vaping-associated lung injury and vitamin E acetate, a toxicant found in bronchoalveolar lavage fluid of some patients who reported using e-cigarettes. Also, nicotine dependency from e-cigarettes may adversely affect brain development in children and adolescents. $^{2}$

The first step in fighting this crisis is to educate children, parents, teachers, and health care professionals about e-cigarette use, including its prevalence, use compared with cigarette smoking, trends among teenagers, marketing techniques, and adverse effects. Fortunately, the US government and medical professionals and organizations have made ongoing efforts to discourage e-cigarette use. For example, the American Academy of Child and Adolescent Psychiatry supports the FDA's regulation of e-cigarette use; encourages using evidencebased treatments for tobacco cessation; advocates for vigorous education regarding adolescent e-cigarette use; and endorses restrictions on e-cigarette advertisement. ${ }^{6}$ We strongly urge clinicians to be vigilant about e-cigarette use in their adolescent patients and to intervene in this public health crisis.

Immad A. Kiani, MD

PGY-3 Psychiatry Resident Christiana Care Health Services

Department of Psychiatry Wilmington, Delaware

Narpinder K. Malhi, MD

Child and Adolescent Psychiatrist Christiana Care Health Services Wilmington, Delaware

Disclosures: The authors report no financial relationships with any companies whose products are mentioned in this article, or with manufacturers of competing products.

doi: $10.12788 /$ cp.0043

\section{References}

1. Adams J. Surgeon General's advisory on e-cigarette use among youth. US Department of Health \& Human Services. https://e-cigarettes. surgeongeneral.gov/documents/surgeongenerals-advisory-on-e-cigarette-use-amongyouth-2018.pdf. Published 2018. Accessed August 7, 2020

2. US Federal Drug and Drug Administration. Results from 2018 National Youth Tobacco Survey show dramatic increase in e-cigarette use among youth over past year. https://www.fda.gov/ news-events/press-announcements/results2018-national-youth-tobacco-survey-showdramatic-increase-e-cigarette-use-among-youthover. Published November 15, 2018. Accessed August 7, 2020.

3. Johnston LD, O'Malley PM, Miech RA, et al. Monitoring the future national survey results on drug use, 1975-2016: overview, key findings on adolescent drug use. The University of Michigan Institute for Social Research. https://files.eric. ed.gov/fulltext/ED578534.pdf. Published January 2017. Accessed August 7, 2020.

4. Layden JE, Ghinai I, Pray I, et al. Pulmonary illness related to e-cigarette use in Illinois and Wisconsin-final report. N Engl J Med. 2020;382(10):903-916.

5. Blount BC, Karwowski MP, Shields PG, et al; Lung Injury Response Laboratory Working Group. Vitamin E acetate in bronchoalveolarlavage fluid associated with EVALI. N Engl J Med. 2020;382(8):697-705.

6. Electronic cigarettes. The American Academy of Child and Adolescent Psychiatry. https://www. aacap.org/AACAP/Policy_Statements/2015/ Policy_Statement_on_Electronic_Cigarettes.aspx. Published June 2015. Accessed August 7, 2020. 